\title{
CONTROL STRATEGY FOR A HIGH SPEED SRM FED FROM A PHOTOVOLTAIC SOURCE
}

\author{
Ahmed Said Oshaba1, 2 \\ 1-Power Electronics \& Energy Conversion Dep., Electronics Research Institute (ERI) \\ NRC Blg., El-Tahrir St., Dokki, 12311-Giza, Egypt \\ 2. Jizan University, Faculty of Engineering, Electrical Engineering Department, KSA \\ E-mail: oshaba68@hotmail.com,
}

\begin{abstract}
High speed switched reluctance motors (SRMs) have recently been gaining attention as contenders in many variable speed drive applications. This has also been stimulated by recent advances in power electronic technology which enables this drive system for many applications such as high speed water pump and space and military applications. This paper presents the design and control of high speed four phases SRM suitable for high speed water pumping and other high speed variable load applications. The dynamic load characteristic and the SRM operation modes have been studied and a novel cascade control strategy is designed and implemented using the MathLap Simulink. The SRM drive system is tested and encouraging results were obtained. The results are of prime importance in the developments of rural and remote areas and also for space and military applications
\end{abstract}

Keywords: SRM, PV system, high speed Controller, Torque Controller, Variable Load

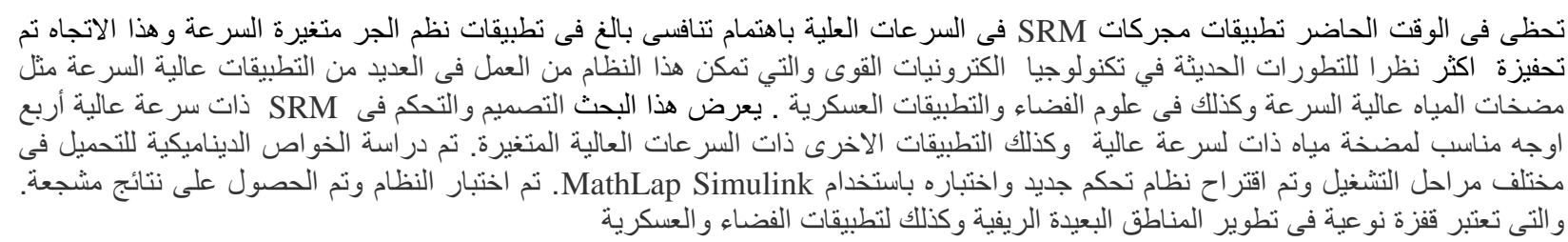

\section{Introduction}

High speed gearless electrical machines find many applications as spindle motors, pump motors, large chiller motors, gas generators, electrical vehicle (EV) and aircraft generators[1-4]. It is known that speed of a.c. machines increases with increase in the input frequency and increasing the input frequency reduces the dimensions of electrical machines This id due to that the electromagnetic torque is proportional to the electromagnetic power and number of pole pairs and inversely proportional to the frequency. However, such high speed is limited and depends on the number of stator poles. This is not the case for SRM in which speeds can increase up to flux saturation limits where the value of flux depended on the voltage value [1-9].

An important consideration in the selection of motors for high speed applications is cost, weight and efficiency. A heavy motor will increase the overall weight of the vehicle (for system example) resulting in lower acceleration and reduced overall performance. A motor that is specifically designed for high speed applications is a better choice than purchasing a standard motor. Switched reluctance motors (SRMs) are a good choice for this system as they are relatively cheap, robust, and can be designed to have minimum weight [15]. The recent advances in power electronics technology have made SRM an attractive candidate for high speed applications. This is due the fact that many desirable features such as simple and rugged construction. Also, SRM manufacturing technology offers an impressive list of advantages that makes industrial users seriously looking for switched reluctance motor drives [1-4].

This paper presents the design of a high speed, four phases, 8/6 poles SRM suitable for high speed

Applications. The design of control system for the SRM for a wide range of dynamical loads is detailed. 


\section{Construction of SRM}

Increasing the value of the SRM speed corresponding to input voltages requires the increase of saturation limits of stator flux linkage. This leads to increase the value of inductance at the aligned position enabling SRM speed to reach 14000 RPM with a balanced increase of the value of input voltage.

The motor considered in this study is a four phases $8 / 6$ poles SRM ( 8 stator poles, 6 rotor poles) has doubly salient construction. Usually the number of stator and rotor poles is even and the construction of the SRM is shown in Fig 1.

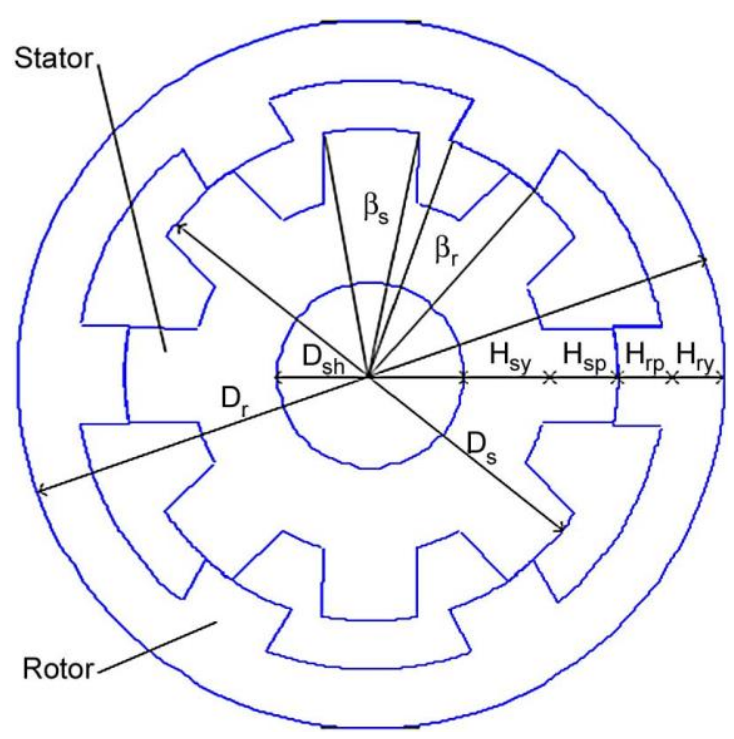

Fig. 1 The SRM 8/6 poles construction.

This design procedure considered a four-phase SRM as it produces less acoustic noise and torque ripple in comparison with the three-phase SRM [1-4]. Torque ripples are undesirable for most variable speed drive applications. Figures 2 and 3 show the flux-linkagecurrent curve and torque-theta curve versus rotor positions for various current levels of SRM. This discrete available data can be extended to be continuous for all $\psi$ and $\mathrm{i}$ values during the period between the positions $\theta=0$ (aligned) and $\quad \theta=2 \pi / \mathrm{N}_{\mathrm{r}}$ (unaligned).

The magnetic behavior of the SRM is highly nonlinear where the static torque produced by one phase at any rotor position is calculated using the following equations [1-15].

$$
\begin{aligned}
& \text { Coenergy }=W^{\backslash}=\int \psi(\theta, i) . . d i \\
& \text { Static Torque }=T_{\text {static }}=d W^{\backslash} / d \theta
\end{aligned}
$$

The results presented in figures 2 and 3 are obtained for a four phase SRM with a special lamination material. absolute rotor position, and rotor speed signals to
It can be observed from these figures of the prototype motor that linear flux linkage characteristics has been obtained in a range of rotor positions between 0 and 15 degrees.

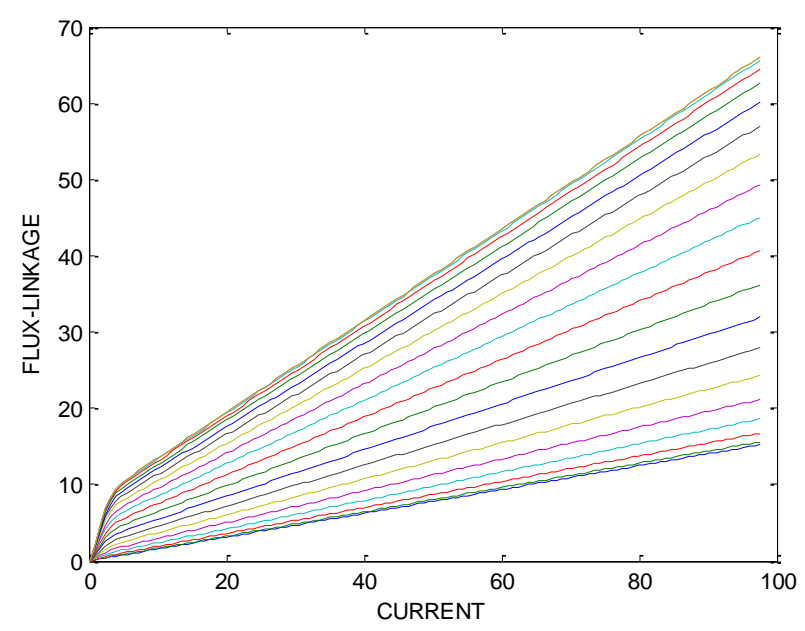

Fig. 2 A family of (flux linkage-current) curves.

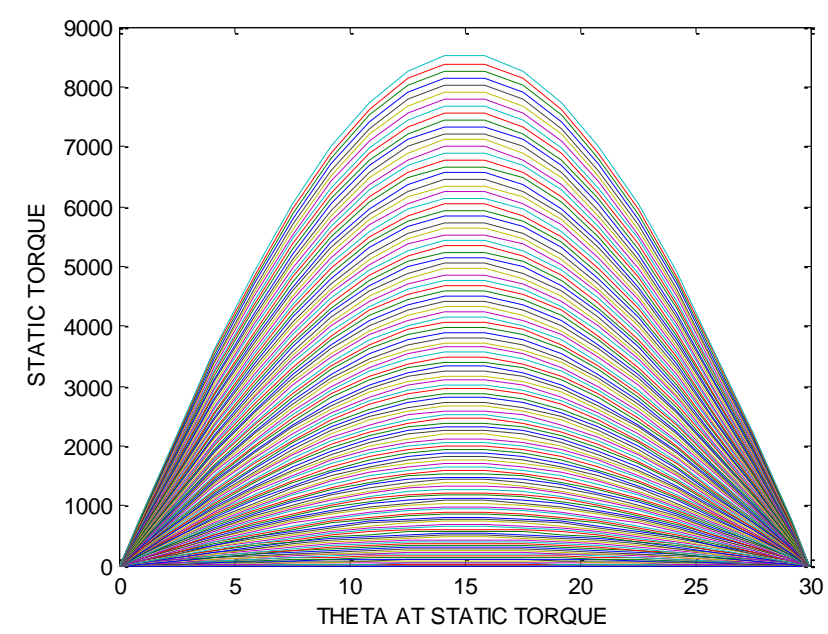

Fig. 3 A family of (theta-static torque) curves.

\section{Modeling and Simulation of SRM}

At present, the maximum power of high speed synchronous generators does not exceed $500 \mathrm{~kW}$. Several airborne power missions are now evolving that will require lightweight multi megawatt electrical power systems, e.g., directed energy weapon (DEW) and airborne radar [1-4]. New high power airborne and mobile military systems will require 1 to $6 \mathrm{MWof}$ electrical power generated at speeds $15 \mathrm{krpm}$. As potential candidates HTS rotor synchronous generators or all cryogenic generators (synchronous or homopolar) have been considered.

The SRM drive depends on the phase current, obtain closed-loop control of current (and hence the 
torque) and speed. Depending on the quality of performance required for a particular application, such as for a low performance, the phase current and speed signals may be dispensed within the control system. The feedback signals are usually measured with transducers, which increase the cost of the electronic controller and its packaging size, reliability and complexity. In the case of a rotor position/speed transducer, the size of the motor housing and the cost are increased significantly. Emerging high-volume applications in heating, ventilation, and air conditioning (HVAC), fans, pumps, home appliances, automobile accessory drives, and many others are cost sensitive. The performance requirements for such applications are not high as is required for machine tool servo drives. The requirement of low cost with high performance for motor drives has placed the agenda of low-cost, sensor-based or sensorless technology at the forefront of present day research and development of motor drives. SRM drives are no exception to this trend, as seen from the high degree of interest shown by industrial and academic researchers worldwide on this topic. Due to the nonlinear nature of the SRM the following steps were made to get an accurate simulation of SRM:

1- The flux-linkage of any phase is computed from the following equation:

$$
\psi(\theta, i)=\int(V-R i) d t
$$

2- The value of phase current can be calculated from the (flux linkage-current) characteristics curves (Fig 2) by using second order interpolation method by used them the flux linkage value $(\psi)$ and rotor angular displacement $(\theta)$.

3- The value of developed torque can be calculated from the static torque characteristics curves (Fig 3) by using second order interpolation method by used them the current value and $\theta$.

4- The value of actual speed can be calculated from the following mechanical equations:

$$
d \omega / d t=\left(T(\theta, i)-T_{m e c h}\right) / J
$$

5- The value of rotor angular displacement $\theta$ can be calculated from the following equation:

$$
d \theta / d t=\omega
$$

But the angle $\delta$ corresponding to the displacement of phase $\mathrm{A}$ in relation to another phase is given by:

$$
\delta=2 \pi\left(\frac{1}{N_{r}}-\frac{1}{N_{s}}\right)
$$

Also the positive period of phase is determined by the following equation:

duty period $=2 \pi\left(\frac{1}{q N_{r}}\right) C_{r}$

And $\mathrm{C}_{\mathrm{r}}$ can be calculated by the following equation.

$$
C_{r}=2 \pi\left(\frac{1}{\beta_{r}}-\frac{1}{\beta_{s}}\right)
$$

\section{Photovoltaic Energy Source}

Photovoltaic (PV) power systems convert sunlight into electricity directly. Research and development efforts are under way to improve efficiency and reduce cost of photovoltaic power systems in applications ranging from roof-top residential to large industrial or electric utility sites. Using of PV power in drive system application are increasing these days from directly coupling with the dc motors to sophisticated ac motor drive systems. SRM is one of these motors that need to supply its phases with dc current one phase at a time. The current is fed to the motor via buck boost $\mathrm{dc} / \mathrm{dc}$ converter with variable duty ratio to extract the maximum power of the PV system and fed the motor with necessary voltage and current to overcome the motor speed and torque requirements [26 29].

\section{Control Strategies}

Conventional control techniques such as voltage, PID, and hysteresis control schemes only are not effective control tools for SRM. This is due to such control systems produce more noise and torque ripples which adversely affect the performance of SRM [15-25]. Therefore, search for alternative control methods which achieve the required control action without adverse effects on motor performance is required. Therefore, this paper presents a control strategy for SRM which avoid problems in using conventional control techniques with this type of motors as well as overcomes problems due to high speed operation. It has been observed that at high speed, SRM exhibit high oscillation about the reference speed which presents instability and adversely affect the motor performance. Therefore, the control strategy proposed in this paper is based on the following introducing three different control loops to provide stable operation at such a high speed. The function of the three control loops can be summarized as follows:

In this case, three controllers are used: 1- turn on controller for starting, 2- speed controller in speed loop 3- torque controller (current controller) in torque loop for 
constant speed at variable load torque. The overall controller system is shown in Fig. 4

\section{Turn on control}

The introduction of integral control for nonlinear system in a control system eliminates the steady-state error. Integral control creates a restoring force that is proportional to the sum of all past errors multiplied by time, as expressed in Eq. 9.

The algorithm of controller can be given as follows:

$$
\operatorname{err}(t)=\operatorname{ref}(t) .-\operatorname{act}(t)
$$

where $\operatorname{act}(t)$ is the actual output of the system, $\operatorname{ref}(t)$ is the reference input of the system, $\operatorname{err}(t)$ is the error signal between $\operatorname{act}(t)$ and $r e f(t)$.

For a constant value of error, the value of $\Sigma(E \Delta t)$ will increase with time, causing the restoring force to get larger and larger. Eventually, the restoring force will get large enough to overcome friction and move the controlled variable in a direction to eliminate the error.

The control action can be obtained as follows:

$u(t)=K_{p} . . e r r(t) .+. K_{i} . . \int \operatorname{err}(t) . . d(t)$

Where $u(t)$ is the output of controller, $K_{p}$ and $K_{i}$ are proportional and integral gains respectively and this gains are adaptation to obtain a good model for starting.

\section{Speed Control}

The output of speed controller is determined by the following equation:-

$u(t)=G_{w} \cdot \operatorname{err}(t)$

$$
\text { Where:- } \quad G_{w}(s)=K_{n} /\left(1+T_{w} S\right) \text {. }
$$

\section{Torque Control}

According to the quasi-linear model of SRM, the average torque equation can be obtained as equation 12 when the phase current is flat topped .

$$
\begin{gathered}
T_{a v}=\frac{m \cdot N_{r} V_{s}^{2}}{2 \pi \omega_{r}^{2}}\left(\theta_{o f f}-\theta_{1}\right) * \\
{\left[\frac{\theta_{1}-\theta_{o n}}{L_{\min }}-\frac{1}{2} \frac{\theta_{o f f}-\theta_{1}}{L_{\max }-L_{\min }}\right]}
\end{gathered}
$$

Where Tav is the average torque, $\mathrm{m}$ is the number of motor phase, $\mathrm{Nr}$ is the number of rotor poles, $\mathrm{Vs}$ is the power supply voltage, $\omega r$ is angular speed of the rotor, $\theta$ on is the angle of starting the excitation, $\theta$ off is the angle of switching off the excitation, $\theta 1$ is the starting angle of the phase inductance increasing, Lmax and Lmin are the maximum and minimum value of phase inductance, respectively.

The total differential equation of Tav can be written in a simplified form as :

$$
\Delta T_{a v}=K_{u} . . \Delta V_{s}-K_{w} . . \Delta \omega_{r}
$$

The increment of the average torque also can be indicated as

$$
\Delta T_{a v}=J \frac{d \Delta \omega_{r}}{d t}+F \cdot \Delta \omega_{r}+\Delta T_{L}
$$

Where $\mathrm{J}$ is rotary inertia, $\mathrm{F}$ is damping coefficient, $\mathrm{T}_{\mathrm{L}}$ is load torque.

The voltage chopping can be treated as a sampling process of the controller's output $\triangle \mathrm{VASR}$, and the amplification factor is $\mathrm{KC}$. The small-signal model of power inverter can be given as

$$
\begin{aligned}
& \Delta V_{s}(s)=K_{C} \frac{1-e^{-T_{s}}}{S} . \Delta V_{A S R}(s) \\
& =K_{C} \frac{T}{1-T_{s}} \Delta V_{A S R}(s) \\
& u(t)=K_{t} . . e r r(t) .
\end{aligned}
$$

Where $K_{t}$ is a adaptive torque gain and the $u(t)$ the output of torque controller but to obtain from this controller the constant speed at variable load torque. 


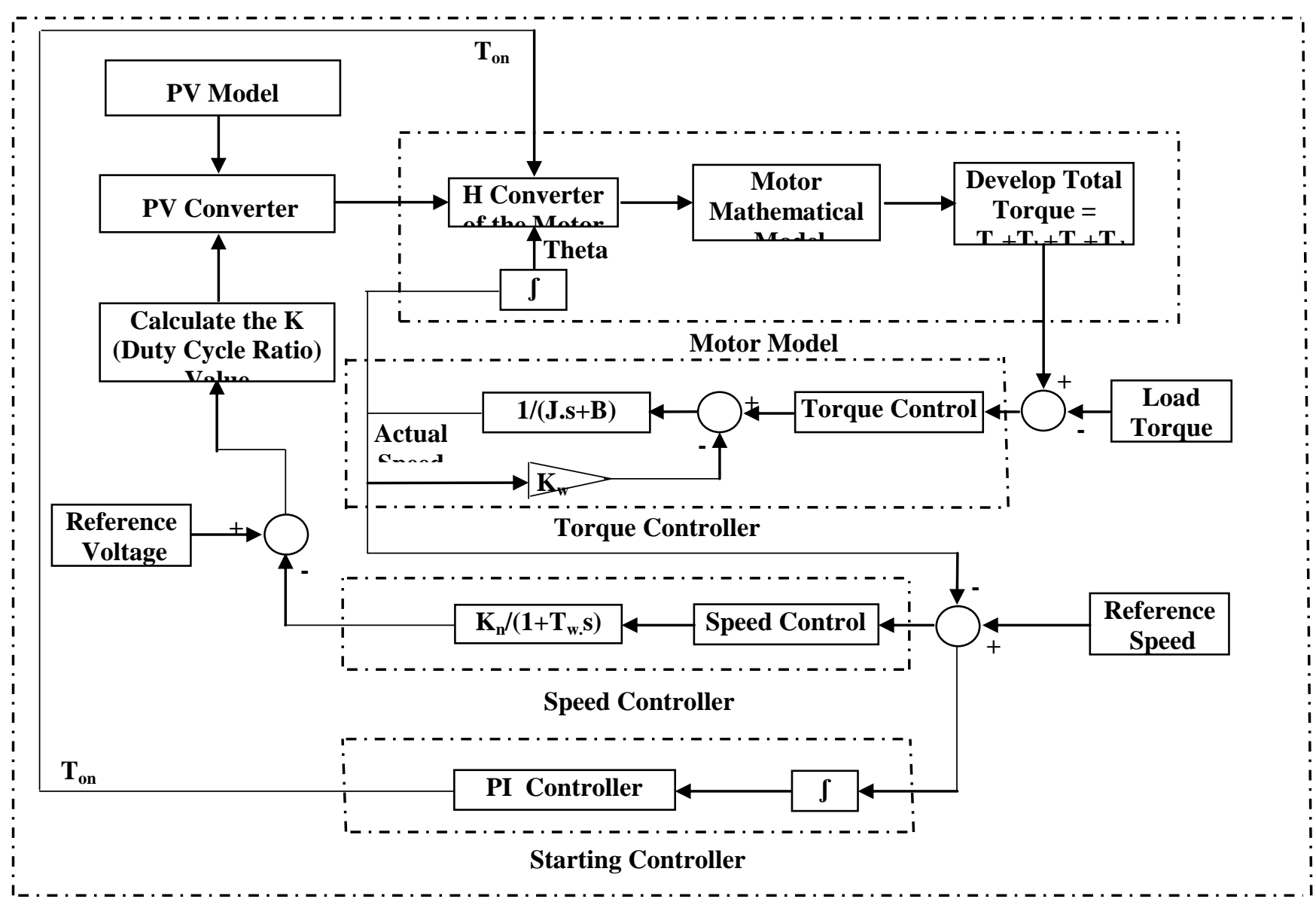

The Overall System (PV, Motor and Control Model)

Fig. 4 Simplified model and control system for SRM.

\section{System Result}

The proposed controller is implemented for using the variable torque drive and pup loads shown in Figs 5 and 6 . The pump load is represented as follows [26]:

$T p_{d e}=0.005+0.00004 \omega_{r} .+0.0001 \omega_{r}^{1.8}$.

The corresponding four phase's currents are shown in Figs 7-10.

During these tests, it has been observed the actual motor speed, under all load conditions, tracks the reference speed over the whole operation range from 0 to 13700 RPM without an overshoot or steady state errors. Figure 12 illustrates one pulse for four phases test result which show that the angle between phases is $15^{\circ}$. And the dwell angle (difference between Toff and Ton angle) is kept fixed and each phase pulse train is phase shifted by: $\left(15 * C_{r}-T_{o n}=10.5^{\circ}\right)$.

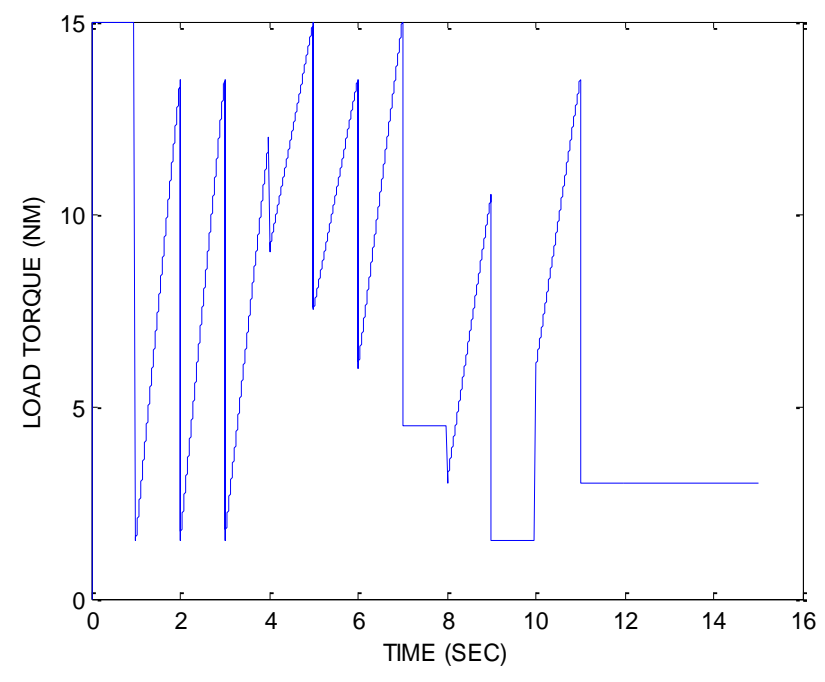

Fig. 5 load torque versus time. 


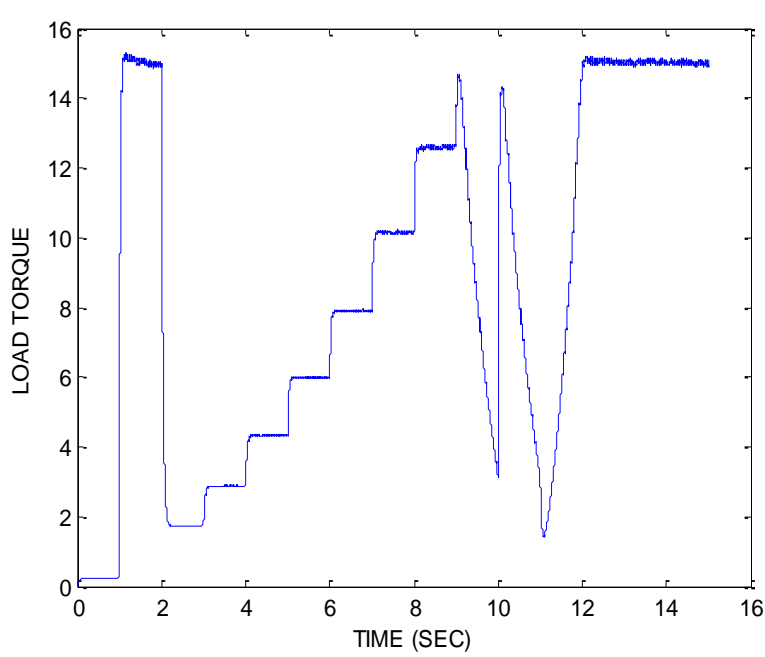

Fig. 6 Pump load variation.

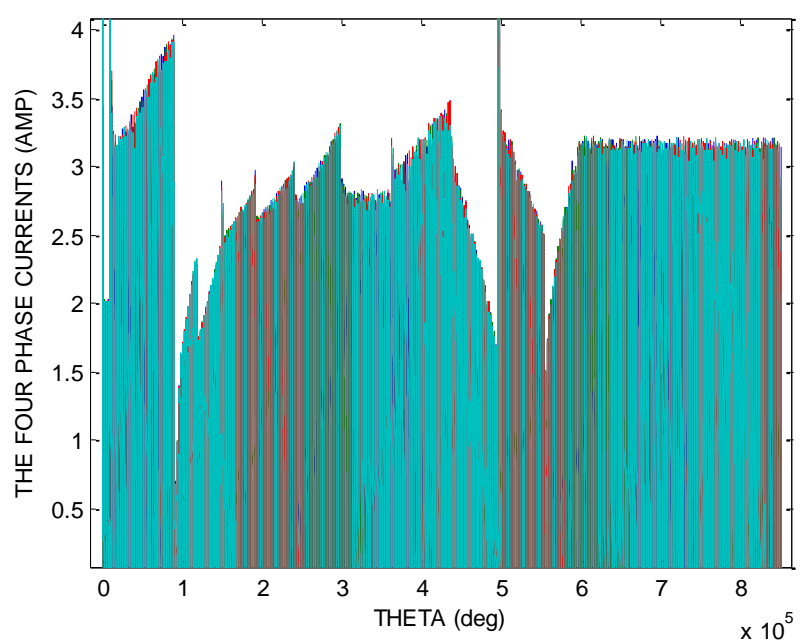

Fig. 7 Four phase instantaneous current, variable load.

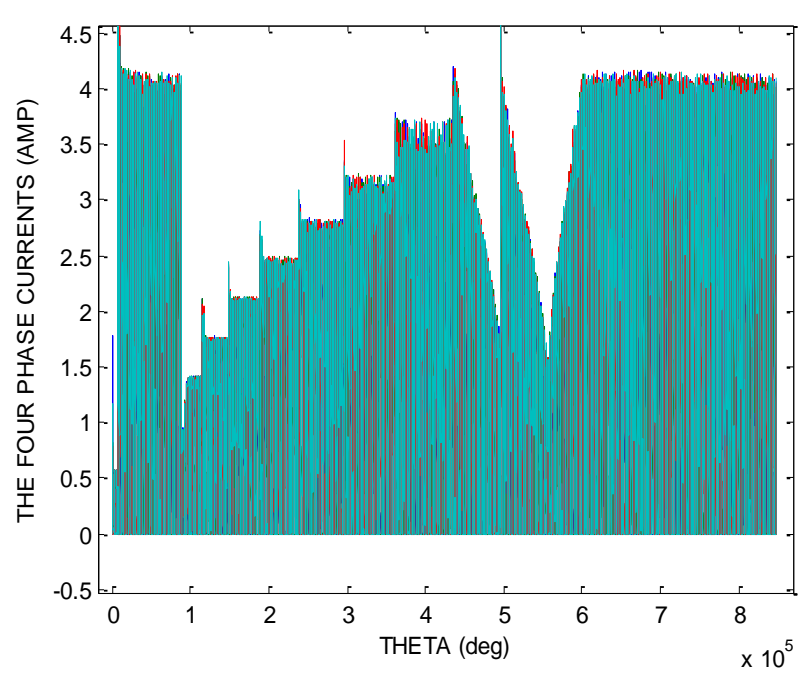

Fig. 8 Four phase instantaneous current, Pump load.

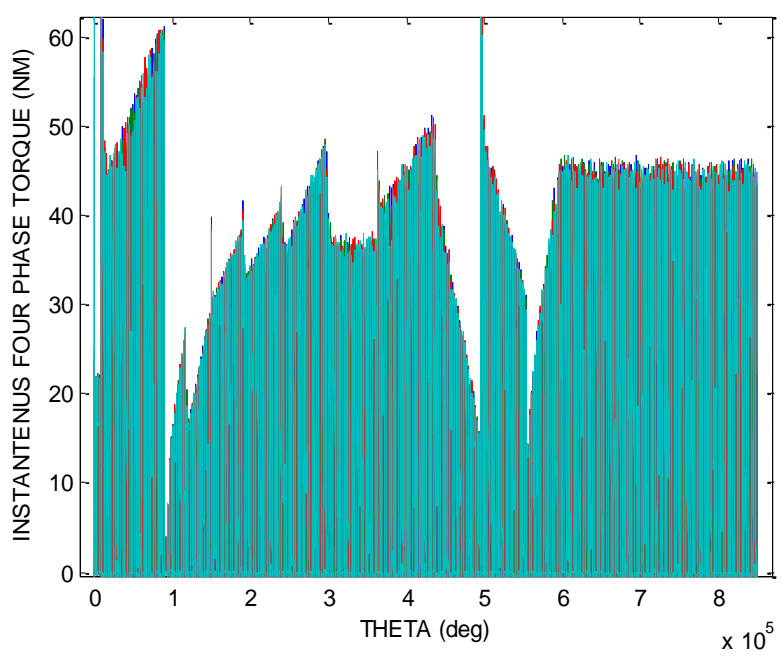

Fig. 9 Four phase instantaneous current, variable load.

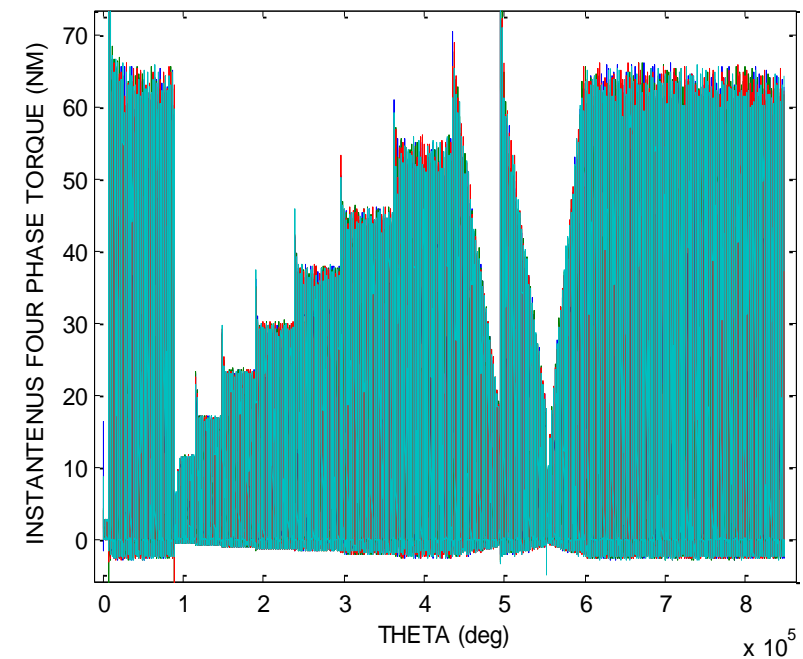

Fig. 10 Four phase instantaneous current, Pump load.

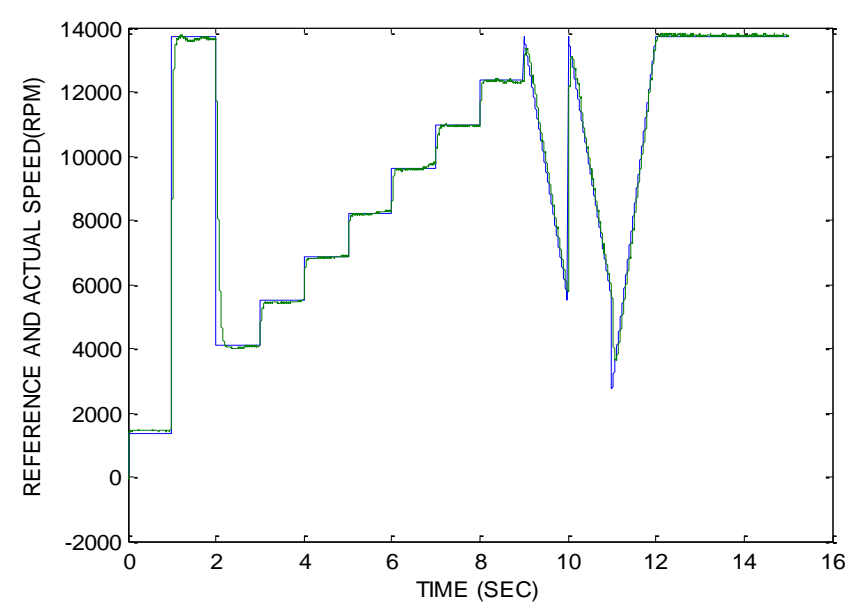

Fig. 11 Actual and reference speed versus time for variable and pump loads. 


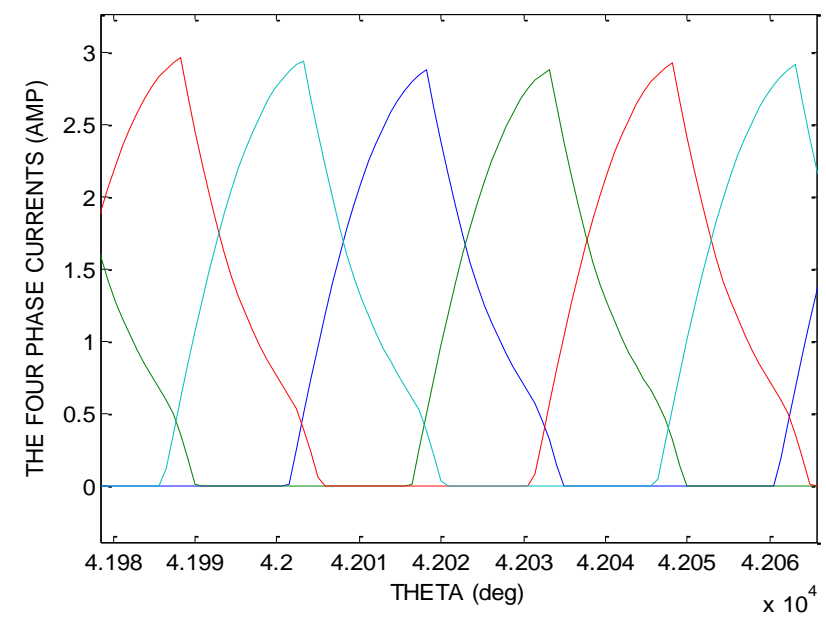

Fig. 12 The four phase instantaneous stator current at high speed with variable load torque.

\section{Conclusions}

This paper described the design and implementation of a control strategy for high speed switched reluctance motor. The control action is divided into three main loops. The turn on control loop is equipped with an integral action deduce the turn on time and eliminates steady state errors so that no high frequency oscillations occur about the output speed which is of prime importance in high speed drive applications. A torque and speed control loops are added to provide accurate control of motor speed at all loads. The control strategy has been tested using fast varying dynamic load and also for a pump load. The results show that the controller was able to track the reference speed without an overshoot at all speed ranges up to $14000 \mathrm{rpm}$. The results also show that the position estimation method used is very effective from starting to steady state. The results also show the fast response of the controller and that the system is critically damped with minimum torque ripples and speed deviations about the reference speed.

\section{References}

[1] T. Uematsu, R. S. Wallace "Design of a 100kW Switched Reluctance Motor for Electric Vehicle" IEEE Transactions on Industrial Electronics, vol. 49, no 1, pp 160-170, Feb 2002.

[2] T.J.E. Miller, "Switched Reluctance Motor and Their Control", Magna Physics and Clarendon Press, Oxford, 1993.

[3] T.J.E. Miller, "Optimal Design of Switched Reluctance Motors" IEEE Transactions on Industrial Electronics, vol. 49, no 1, pp 160-170, Feb 2002.

[4] MagNet 6.2.2 (2001), "Finite-element package for electromagnetic analysis", Infolytica Corporation, Montreal.
[5] K. M. Rahman and S. E. Schulz, "Design of high efficiency and high density switched reluctance motor for vehicle propulsion", IEEE Trans. Ind. Appl., vol. 38, no. 6, pp. 1500-1507, Nov./Dec. 2002.

[6] A. K. Jain and N. Mohan, "Dynamic modeling, experimental characterization, and verification for SRM operation with simultaneous two-phase excitation", IEEE Trans. Ind. Electron., vol. 53, no. 4, pp. 1238-1249, Jun. 2006.

[7] Jae-Hak Choi, Joonseon S. Ahn and Ju Lee, "The Characteristic Analysis of Switched Reluctance Motor Considering DC-Link Voltage Ripple on Hard and Soft Chopping Modes", IEEE transactions on magnetics, Vol. 41, No.10, pp. 4096-4098, Oct. 2005.

[8] J. G. Amoros and P. Andrada, "Sensitivity analysis of geometrical parameters on a double-sided linear switched reluctance motor", IEEE Trans. Ind. Electron., vol. 57, no. 1, pp. 311-319, Jan. 2010.

[9] R. Krishnan, "Switched Reluctance Motor DrivesModeling, Simulation, Analysis Design, and Applications", Boca Raton, FL: CRC Press, 2001.

[10] Dan Jones, "Present and future applications of switched reluctance motors and drives", SMIC '99 conference, October 1999, Tokyo, Japan.

[11] J.M. Stephenson and J. Corda "Computation of Torque Current in Double Salient Reluctance Motors From Nonlinear Magnetization Data", proceedings IEE,vol.126, No.5, May 1979, pp. 393-396. 
[12] J. Corda and J.M. Stephenson "Analytical Estimation of the Minimum and Maximum Inductances of a Double-Salient Motor ", Proceedings of the International Conference on Stepping Motors and Systems, University of Leeds, UK, September 1979, pp. 50-59.

[13] Shuyu Cao, and K.J. Teseng, "A New Method for Self-Learning Techniques”, ENE'93, pp. 1419.

[15] Ahmed Oshaba, "Analysis and Control of SRM", Ph.D. Thesis, Cairo Univ., FOE, April, 2004.

[16] X. D. Xue, K. W. E. Cheng, and S. L. Ho, "A position stepping method for predicting performances of switched reluctance motor drives", IEEE Trans. Energy Convers., vol. 22, no. 4, pp. 839-847, Dec. 2007.

[17] J.J. Gribble P.C. Kjaer and T.J.E. Miller "Optimal Commutation in Average Torque Control of Switched Reluctance Motors", IEE Proc.-Electric Power Appl., vol. 146, No. 1, January 1999, pp. 2-10.

[18] Khwaja M. Rahman, Suresh Gopalakrishnan, Babak Fahimi, Anandan Velayutham Rajarathnam and M. Ehsani "Optimized Torque Control of Switched Reluctance Motor at All Operational Regimes Using Neural Network", IEEE Transations on Industry Applications, vol. 37, NO. 3, May/June 2001, pp. 904-913.

[19] Krzysztof Russa, Iqbal Husain and Malik E. Elbuluk "A Self-Tuning Controller for Switched Reluctance Motors", IEEE Transactions on power electronics, vol. 15, No.3, May 2000.

[20] Chen H. \& Gu J. J. (2010). "Implementation of the Three-Phase Switched Reluctance Machine System for Motors and Generators", IEEE/ASME Transactions on Mechatronics, Vol.15, No.3, June 2010, 421-432, ISSN 1083-4435.

[21] Naayagi R. T. \& Kamaraj V. (2005). "Shape Optimization of Switched Reluctance Machine for Aerospace Applications", Proceedings of 31st Annual conference of IEEE Industrial Electronics Society, pp. 1748-1751, ISBN 07803-9252-3, Raleigh, November 2005, IEEE Industrial Electronics Society, Los Alamitos.

[22] Liu W. \& Song S. (2006). "Application of Fuzzy Control in Switched Reluctance Motor Speed Regulating System", Proceedings of
Accurate Analytical Modeling of Switched Reluctance Motor", PEDES'98 Vol. II, December 1998 pp.540-545.

[14] C. Rochford, R.C. Kavanagh, M.G. Egan and J.M.D. Murphy "Development of Smooth Torque in Switched Reluctance Motors Using

International Conference on Computational Intelligence for Modelling, Control and Automation, pp. 72-72, ISBN 0-7695-2731-0, Sydney, November 2006, Patrick Kellenberger, Sydney.

[23] K. M. Rahman, B. Fahimi, G. Suresh, A. V. Rajarathnam, and M. Ehsani, "Advantages of switched reluctance motor applications to $\mathrm{EV}$ and HEV: Design and control issues", IEEE Trans. Ind. Appl., vol. 36, no. 1, pp. 111-121, Jan./Feb. 2000.

[24] R. B. Inderka, M. Menne, and R. W. A. A. De Doncker, "Control of switched reluctance drives for electric vehicle applications", IEEE Trans.Ind. Electron., vol. 49, no. 1, pp. 48-53, Feb. 2002.

[25] I. Husain and S. A. Hossain, "Modeling, simulation, and control of switched reluctance motor drives", IEEE Trans. Ind. Electron., vol. 52, no. 6, pp. 1625-1634, Dec. 2005.

[26]Dina S M osheba " Photovoltaic System Fed DC Motor Controlled By Converters", M.Sc Thesis, March,2011, Menoufiya University, Egypt.

[27] Yousry Atia, "Photovoltaic Maximum Power Point Tracking Using SEPIC Converter", Engineering Research Journal (ERJ), Shebin El-Kom Journal, Vol.36, No.4, October 2009.

[28] E. Matagne, Chenni R, El Bachtiri R., "A photovoltaic cell model based on nominal data only", International Conference on Power Engineering, Energy and Electrical Drives, 2007. Powereng 2007. 12-14 April 2007 Setubal, Portugal.

[29] M. Zahran, A. Hanafy, 0. Mahgoub and M. Kamel, "FLC Based Photovoltaic Battery Diesel Hybrid System Management and Control", 28th IEEE Photovoltaic Specialists Conference", September 15-22, 2000, Anchorage Hilton, Anchorage, Alaska, USA, 0-7803-5772-8/00@ 2000 IEEE 